\title{
Changes in foliar epicuticular wax and photosynthesis metabolism in evergreen woody species under different soil water availability
}

\author{
S. PEREIRA*, K. FIGUEIREDO-LIMA*, A.F. M. OLIVEIRA*, and M.G. SANTOS*,+ \\ Universidade Federal de Pernambuco, Departamento de Botânica, Recife, PE 50670-901, Brazil ${ }^{*}$
}

\begin{abstract}
Epicuticular waxes (EW) are important for plant physiology as a protective barrier against water loss. Thus, the main goal of this study was to evaluate the ecophysiological performance of Cynophalla flexuosa, an evergreen woody species, under different foliar EW contents. The study was conducted during three periods throughout the year in a seasonally dry tropical forest area. The xylem water potential decreased to $70 \%$ at midday. The main EW components were n-alkane chains, effective in keeping the cuticle impermeability. We analyzed intact leaves and leaves with EW removed. C. flexuosa did not alter its photosynthetic performance throughout the day in leaves where EW was removed, except under the lowest soil water balance. Furthermore, foliar biochemical metabolism activity also was maintained. Thus, photochemical and gas-exchange values showed a high resilience, although soil water availability decreased. These findings highlight that this evergreen woody species performed under semiarid conditions with high foliar dynamic traits.
\end{abstract}

Additional key words: climate change; cuticle; drought tolerance; leaf metabolism; oxidative stress; water deficit.

\section{Introduction}

Cuticular wax is important for gas exchange in plants of semiarid regions (Figueiredo et al. 2012, 2015; Medeiros et al. 2017). The previous studies, under semiarid conditions, were focused on dominant deciduous plants phenology, which is the main mechanism of escape during dry seasons (Poorter and Markesteijn 2008, Lima et al. 2012). On the other hand, there are few evergreen species with sufficient ability to maintain their leaves throughout the dry season without any significant precipitation (Diego et al. 2012, Tomlinson et al. 2013, Santos et al. 2014, Morales et al. 2015, Skelton et al. 2017).

The main mechanisms of drought tolerance for most plants are escape or avoidance. The latter mechanism could keep a high water potential in some species, while others species would tolerate decreasing water potential (Kramer and Boyer 1995). Thus, the evergreen woody species from seasonal dry tropical forest can maintain their water status and consequent survival during periods of low water availability through the relationship among physiological, anatomical, and morphological traits (Lima et al. 2012, Skelton et al. 2017). Among these traits, a cuticle is important due to three different components: waxes, polysaccharide microfibrils, and cutin (Kerstiens 1996). The cuticle is an efficient protective barrier because it reduces infection caused by pathogens and acts by controlling ions and nutrient losses (Guhling et al. 2005). Moreover, it acts against environmental stresses, including drought and high irradiance, by reducing water loss through the epidermis (Riederer and Schreiber 2001).

Among cuticle wax layers, epicuticular waxes (EW) are the last interface between leaf and atmosphere. Thus, it is important for physiology and ecology of plants (Figueiredo et al. 2012, 2015; Medeiros et al. 2017). The EW controls diffusion and reflection, and makes tolerable a radiation intensity reaching active photosystems in the mesophyll (Riederer 2006).

Cuticle can play a decisive protective role for the photosynthetic apparatus under environments with limited water availability and radiation intensity; it justifies studies under field conditions on native plants from SDTF (Medeiros et al. 2017). In semiarid environments, if forecasts of longer droughts and even higher average temperatures are confirmed (IPCC 2013), the ability to tolerate water deficit is fundamental for plant survival (Santos et al. 2014). However, effects of possible changes tend to be even more intense for evergreen woody species (Santos et al. 2014). Indeed, among traits supporting species survival, $69 \%$ are explained by the deciduousness.

\footnotetext{
Received 13 February 2018, accepted 14 June 2018.

${ }^{+}$Corresponding author; phone: +55 81 21268844, fax: +55 81 21267803, e-mail: mauro.gsantos@ufpe.br

Abbreviations: APX - ascorbate peroxidase; CAT - catalase; ETR - electron transport rate; EW - epicuticular wax; FA - total free amino acids; $\mathrm{F}_{\mathrm{v}} / \mathrm{F}_{\mathrm{m}}-$ PSII maximum quantum efficiency; $g_{\mathrm{s}}-$ stomatal conductance; $\mathrm{MDA}-$ malondialdehyde; $P_{\mathrm{N}}-$ net $\mathrm{CO}_{2}$ assimilation; $\mathrm{q}_{\mathrm{P}}-$ photochemical quenching; SDTF - seasonally dry tropical forest; SOD - superoxide dismutase; SS - soluble sugars; TP - total soluble proteins; VPD - vapor pressure deficit; $\mathrm{WUE}_{\mathrm{i}}$ - intrinsic water-use efficiency; $\Phi_{\mathrm{PSII}}$ - operational efficiency of PSII.

Acknowledgements: S. Pereira would like to thank Coordenação de Aperfeiçoamento de Pessoal de Nível Superior (CAPES, Brazil) for the scholarship. This study was funded by CNPq (CNPq-470247/2013-4). A. Oliveira and M. Santos would like to thank CNPq for the fellowship granted.
} 
On the other hand, among evergreens, the stem density can explain 20\% survival (Poorter and Markesteijn 2008).

Low water availability and high radiation, the typical semiarid abiotic factors, lead to changes in the foliar anatomy, reduced photochemical activity, and increased photoprotection mechanisms of photosynthetic machinery (Oliveira et al. 2017). Thus, gas exchange is affected by reducing stomatal conductance and consequently the net $\mathrm{CO}_{2}$ assimilation (Chaves et al. 2016). Furthermore, one expects imbalance in leaf biochemical metabolism, especially of sugars (Oliveira et al. 2017).

This study aimed to evaluate the role of foliar EW in the maintenance of photosynthesis and metabolism under the influence of water availability in semiarid field conditions. A tropical evergreen species, Cynophalla flexuosa, was studied. Our hypothesis was that EW shows intense dynamism in composition and content depending on changes in environment and water availability in order to protect the leaf metabolism and to control water loss by the epidermis.

\section{Materials and methods}

Plant material and study site: The evergreen woody species Cynophalla flexuosa (L.) J. Presl. (Capparaceae) was studied. It is native to Brazil and has arboreal growth habit. The study was carried out in a semiarid region of northeast Brazil (795'37"S, 38²9'72"W; $511 \mathrm{~m}$ a.s.1.) in an open SDTF area. According to Köeppen classification, the climate is Bsh type with rainy season from January to May, and dry season from June to December, with rarely rain events and average annual rainfall of around $750 \mathrm{~mm}$. Litosolic Neosols and Luvisols are predominant in the area.

At the beginning of the study, ten adult individuals approximately $3-\mathrm{m}$ high and located in the same soil type were identified. Samplings were performed in July and December 2014, and February 2015, in order to evaluate different periods. Thus, measurements were planned to occur in the reference periods of high (HWB), middle (MWB), and low (LWB) soil water balance according to the historical series of precipitation (Fig. $1 A, B$ ).

Leaves were fully expanded and matured, and two formats were determined: intact - without any epicuticular wax removal (total wax) - and with epicuticular wax removed mechanically keeping only intracuticular wax (intracuticular wax). Both were side by side located in the same branch but at opposite sides.

Soil humidity, water balance and xylem water potential $\left(\Psi_{\mathrm{x}}\right)$ : Samples were collected to measure soil moisture at a depth of $30 \mathrm{~cm}$. The soil was weighed when wet and then heated at $60^{\circ} \mathrm{C}$ until reaching constant mass. The moisture was calculated by the difference between the masses. The water balance was measured using the ETP methodology according to the spreadsheet provided by Rolim et al. (1998). The environmental data on rainfall and temperature were consulted on the Agronomic Institute of Pernambuco (IPA) and Agritempo websites, respectively.

The xylem water potential $\left(\psi_{\mathrm{x}}\right)$ was measured to verify the shoot water status through the Schölander pressure chamber (PMS Instrument Company, USA Model 600D$O R$, USA) in three plants per treatment during the day at the following times: 4:00, 10:00, 13:00, 16:00, and 18:00 h.

Leaves with epicuticular wax removed: The leaves with EW removed (-EW; intra-wax leaves) were analyzed with Arabic gum (Sigma-Aldrich, France) solution $\left(1.5 \mathrm{~g} \mathrm{~mL}^{-1}\right)$ which was applied on ten fully expanded and mature leaves from different branches. A thin solution layer was applied with the aid of a brush to the most sun-exposed leaf side (adaxial face) in a ratio of $0.1 \mathrm{~mL} \mathrm{~cm}$. After complete drying (at least $1 \mathrm{~h}$ ), the gum was removed according to the methodology proposed by Jetter and Schäffer (2001). The
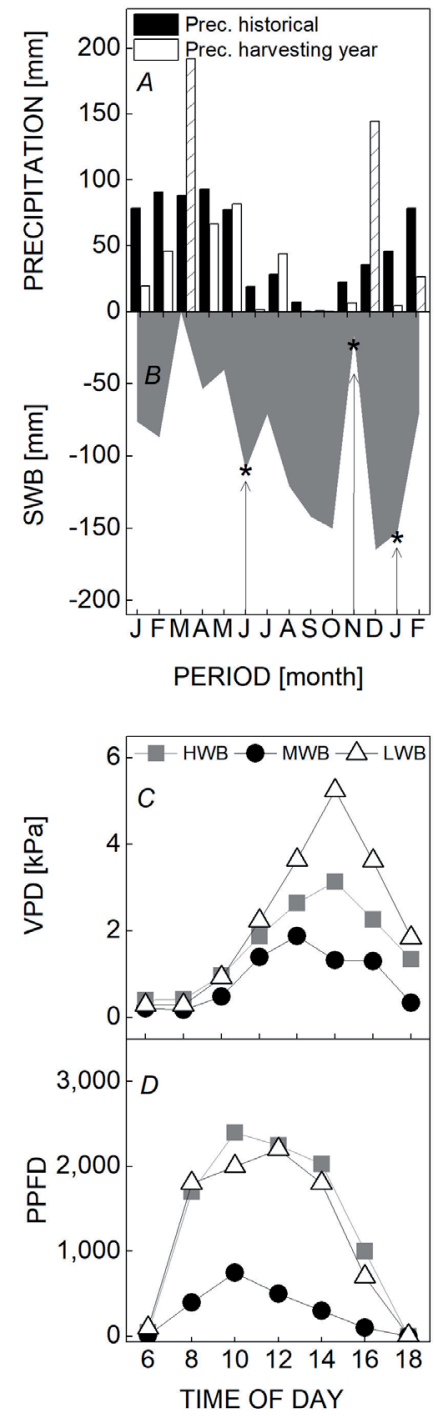

Fig. 1. Environmental data of the studied area. $(A)$ Annual historical precipitation monthly average (2009-2015) and precipitation during the year of study at the municipality of Serra Talhada, PE, Brazil; $(B)$ soil water balance (SWB) between January 2014 and February 2015; $(C)$ vapor pressure deficit (VPD), and $(D)$ photosynthetical photon flux density (PPFD) in the period of the experiment with Cynophalla flexuosa throughout the day and during different soil water balance levels: HWB (high water balance), MWB (middle water balance), and LWB (low water balance). 
gas exchange and the chlorophyll (Chl) $a$ fluorescence were measured $48 \mathrm{~h}$ after EW removal from the leaves.

Gas exchange: The net $\mathrm{CO}_{2}$ assimilation $\left(P_{\mathrm{N}}\right)$, stomatal conductance $\left(g_{\mathrm{s}}\right)$, and transpiration rate $(E)$ were measured with the infrared gas analyzer (IRGA) ( $L C i$ model, $A D C$, Hoddesdon, UK) on leaves completely expanded and the same branch for the two treatments. The intrinsic wateruse efficiency $\left(\mathrm{WUE}_{\mathrm{i}}\right)$ was obtained from the ratio of $P_{\mathrm{N}} / g_{\mathrm{s}}$. Measurements were taken from four individuals of C. flexuosa during one day of each month within the period of local sunlight with intervals of two hours starting at 06:00 $\mathrm{h}$ and ending at 18:00 h. The leaf temperature was measured with infrared thermometer (ST-600, Incoterm, China) placed at $0.3 \mathrm{~m}$ from each leaf used to the gasexchange measurements.

Chl $\boldsymbol{a}$ fluorescence: The Chl $a$ fluorescence were analyzed in fully expanded and healthy leaves, one leaf per treatment (total wax and intracuticular wax, C vs. -EW), with the aid of fluorometer (FluorPen FP100, Photon Systems Instruments, Czech Republic). Chl $a$ fluorescence was obtained after covering leaves with dark clip for a 30-min period. The operational efficiency parameters of PSII $\left(\Phi_{\text {PSII }}\right)$, maximum quantum efficiency of PSII $\left(\mathrm{F}_{\mathrm{v}} / \mathrm{F}_{\mathrm{m}}\right)$, photochemical quenching $\left(\mathrm{q}_{\mathrm{P}}\right)$, nonphotochemical quenching (NPQ), and electron transport rate (ETR) were addressed according to Maxwell and Johnson (2000). Measurements were taken every 2-h intervals at the same time as gas-exchange measurements using leaves at the same branch.

Biochemistry and oxidative stress analyses: Leaves from both treatments were collected at 14:00 h, frozen in liquid nitrogen, and stored in a freezer at $-80^{\circ} \mathrm{C}$. We determined foliar contents of soluble sugars (SS) (DuBois et al. 1956), fractionated sugars (sucrose and fructose) (Handel 1968, Foreman et al. 1973), total free amino acids (FA) (Moore and Stein 1954), proline (Bates et al. 1973), total soluble proteins (TP) (Bradford 1976), Chl $a$ and Chl $b$, and carotenoids (Car) (Lichtenthaler 1987). The leaf extract was obtained using $80 \%$ ethanol (Robbins and Pharr 1988, Trethewey et al. 1998) for analysis of soluble sugars, sucrose, fructose, and amino acids. The anhydride glucose $\left(180 \mu \mathrm{g} \mathrm{mL}^{-1}\right)$ was used for standard curve at absorbance of $490 \mathrm{~nm}$ (Geneses 10S UV-VIS, Thermo Scientific, USA).

The main compounds of the antioxidative cycle in leaves used as control and those without EW were analyzed to determine the enzymatic activity of superoxide dismutase (SOD, EC 1.15.1.1), ascorbate peroxidase (APX, EC 1.11.1.11), and catalase (CAT, EC 1.11.1.6) from $50 \mathrm{mg}$ of leaf tissue. The buffer with $100 \mathrm{mM} \mathrm{K}$-phosphate, $0.1 \mathrm{mM}$ EDTA, $5 \mathrm{mM}$ dithiothreitol, $10 \mathrm{mM}$ 2-mercaptoethanol, $0.1 \%$ (v/v) Triton $X-100$, and 30\% polyvinylpyrrolidone was used to measure the activity of SOD. Thus, the SOD activity was determined by measuring inhibition of the photochemical reduction of nitroblue tetrazolium at $560 \mathrm{~nm}$ (Giannopolitis and Reis 1977). The reaction mixture of $3 \mathrm{~mL}$ consisted of $75 \mu \mathrm{mol} \mathrm{NBT,} 2 \mu \mathrm{mol}$ riboflavin, $0.013 \mathrm{~mol}$ of methionine, $0.1 \mu \mathrm{mol}$ of EDTA,
$0.05 \mathrm{~mol}$ of K-phosphate buffer ( $\mathrm{pH} 7.8$ ), and $100 \mu \mathrm{L}$ of the enzyme extract. Test tubes containing the mixture were placed in a wooden box with two fluorescent lamps [40 W], reaching irradiance of $130 \mu \mathrm{mol}$ (photon) $\mathrm{m}^{-2} \mathrm{~s}^{-1}$ at the surface of the reaction tube. The reaction started by switching on the light for $10 \mathrm{~min}$. After that, the light was switched off in order to terminate the reaction, and the absorbance at $560 \mathrm{~nm}$ was recorded. A non-irradiated reaction mixture, which did not develop any color, served as the control, and its absorbance was subtracted from the sample absorbance measurements. One unit of SOD activity was defined as the amount of enzyme that resulted in $50 \%$ inhibition in the rate of NBT reduction. The extraction buffer for CAT and APX contained $100 \mathrm{mM}$ K-phosphate, 2 mM EDTA, $20 \mathrm{mM}$ ascorbic acid, and 30\% polyvinyl-pyrrolidone. Activity of CAT was estimated by measuring the decomposition rate of $\mathrm{H}_{2} \mathrm{O}_{2}$ at $240 \mathrm{~nm}$ using an extinction coefficient of $36 \mathrm{mM} \mathrm{cm}^{-1}$ (Havir and McHalle 1987). APX activity was determined by reducing $\mathrm{H}_{2} \mathrm{O}_{2}$ to water with ascorbate as reducing agent and by monitoring the decrease in absorbance at $290 \mathrm{~nm}$. Thus, the enzyme activity was calculated using the extinction coefficient of $2.8 \mathrm{mM} \mathrm{cm}^{-1}$ (Nakano and Asada 1981). Finally, the unit of CAT or APX was defined as the amount of enzyme requisite to oxidize $1 \mu \mathrm{mol}$ of $\mathrm{H}_{2} \mathrm{O}_{2}$ or ascorbate per min calculated per protein. The accumulation of malondialdehyde, MDA), the reactive oxygen species (ROS), and $\mathrm{H}_{2} \mathrm{O}_{2}$ were determined in the leaf following the methodology described by Cakmak and Horst (1991) and Alixieva et al. (2001), respectively, to verify the plasma membrane lipid peroxidation. The molar extinction coefficient (155 $\mathrm{mM} \mathrm{cm} \mathrm{cm}^{-1}$ ) was used to calculate the MDA concentration. For all analyzes UV-Vis spectrophotometer (Genesys 10s, Thermo Scientific, USA) adjusted to each organic compound at specific wavelengths.

Extraction and chromatographic analysis of epicuticular wax: Leaves were subjected to three successive extractions of total wax with chloroform for $30 \mathrm{~s}$ on a delimited area of $1.13 \mathrm{~cm}^{2}$. Prior to GC analysis, a defined amount of n-tetracosane was added to the extract which was derived prior with BSTFA [N,Obis(trimethylsilyl) trifluoroacetamide] in pyridine $\left(70^{\circ} \mathrm{C}\right.$ for $30 \mathrm{~min}$ ). The quantitative analysis was recorded using gas chromatograph (Shimadzu GC-17A, Kyoto, Japan) equipped with $D B-5$ capillary column $(30 \mathrm{~m} \times 0.25 \mathrm{~mm}$ $\times 0.25 \mu \mathrm{m}, J \& W$ Scientific, Folsom, CA, USA). Helium was a carrier gas at constant flow of $1 \mathrm{~mL} \mathrm{~min}^{-1}$ and a 1:39 split. The initial temperature was $150^{\circ} \mathrm{C}$ during $3 \mathrm{~min}$, increased $10^{\circ} \mathrm{C} \mathrm{m^{-1 }}$ up to $280^{\circ} \mathrm{C}$, and maintained for $30 \mathrm{~min}$. The injector and detector temperature was 250 and $290^{\circ} \mathrm{C}$, respectively. The relative percentage of individual components was expressed as percent peak area relative to the total peak area. Compounds identification was performed by GC coupled to a mass spectrometer ( $G C / M S$ Agilent 6859/5975B) using Agilent J\&W DB-5HT capillary column $(3.0 \mathrm{~m} \times 0.32 \mathrm{~mm} \times 0.10 \mu \mathrm{m})$ and helium as a carrier gas for $1.5 \mathrm{~mL} \mathrm{~min} \mathrm{~m}^{-1}$. The temperature was $100^{\circ} \mathrm{C}$ during $3 \mathrm{~min}$, increasing $5^{\circ} \mathrm{C} \mathrm{min}^{-1}$ up to $320^{\circ} \mathrm{C}$, and maintained for $8 \mathrm{~min}$. Split-less injection was used. The injector, 
transfer line, quadrupole, and ion source temperatures were set at $300,320,150$, and $230^{\circ} \mathrm{C}$, respectively. MS detection was performed with electron ionization (EI) at $70 \mathrm{eV}$ operating in the full-scan acquisition mode in the $40-800 \mathrm{~m} / \mathrm{z}$ range. Peaks were identified by comparison with standard mass spectrum and compounds of Wiley 229 (Wiley, USA) and NIST 08 (NIST, USA) databases. The mean EW content was calculated by the ratio between $\mathrm{EW}$ obtained $(\mu \mathrm{g})$ and leaf area $\left(\mathrm{cm}^{2}\right)$ and expressed as $\mu \mathrm{g} \mathrm{cm}$. Leaves analyzed for intracuticular wax were first submitted to the extraction method performed with Arabic gum. After removing the epicuticular layer, the same procedure previously mentioned for chemical extraction using solvent was performed.

Anatomical analyses: Two recent and mature leaves were collected at same time when other measures were performed. Samples collected were fixed in FAA50 formaldehyde, acetic acid, 50\% ethanol, in the ratio of $1: 1: 18$, respectively, for $72 \mathrm{~h}$, and then transferred to $70 \%$ ethanol for preservation. Optical microscopy (MO) was divided in two steps: transverse sectioning and dissociation. For transverse sectioning, samples were submitted to a series of tertiary ethanol-butanol dehydration (50 to 100\%) and transferred to pure butanol (overnight). After this step, was carried out the infiltration and inclusion in paraffin in butanol-paraffin series $(3: 1,1: 1,1: 3)$ and then transferred to pure paraffin with 2-3 more exchanges. Samples were cut to $10-\mu \mathrm{m}$ thick sections on the Zeiss rotary microtome model HYRAX M55 (Germany), thereafter cut material were fixed to slides. Sections were dewaxed and stained in a dual coloration composed of Alcian blue and safranin, and placed on permanent slides with Canadian balsam (Purvis et al. 1964). The dissociation was performed with a solution of Franklin-hydrogen peroxide and acetic acid $(1: 1)$ to analyze the leaf surface (Franklin 1945). Subsequently, samples were stained with $1 \%$ safranin and prepared on semipermanent slides with 50\% glycerin (Purvis et al. 1964).

Observations and records of the material were performed under a Leica microscope model DM500 (Germany). Micromorphometric analyzes were performed from images: mesophyll thickness (and their parenchyma), abaxial and adaxial epidermis thickness, and total leaf thickness; stomata were counted to determine stomatal density by area $\left(0.5 \mathrm{~mm}^{2}\right)$ as described in detail by Oliveira et al. (2017).

Statistical analyses: We performed analysis of variance (ANOVA) of repeated measures for gas-exchange data, $\mathrm{Chl}$ $a$ fluorescence, xylem water potential, and leaf temperature. Factorial ANOVA was used for biochemical, epicuticular wax, and anatomy data. As categorical variables, we used leaf treatments (total wax and intracuticular wax) and soil water balance levels (high, middle, and low). Moreover, for anatomical parameters, the categorical variables it was adaxial and abaxial faces of the leaf and soil water balance levels (high, middle, and low). Student's and Newman Keul's test at 5\% probability was used when differences were detected, both tests using STATISTICA 8.0 software (Statsoft Inc., Tulsa, USA).

\section{Results}

Environmental conditions: With rainfall even more irregular than the average, the soil water balance was negative throughout the study period (Fig. 1A), characterizing water deficiency. Despite total precipitation being approximately $630 \mathrm{~mm}$ between January 2014 and February 2015, the distribution of rainfall events was irregular. This was reflected in the soil water balance: HWB $=-20 \mathrm{~mm}$, MWB $=-110 \mathrm{~mm}$, and LWB = $-160 \mathrm{~mm}$ (Fig. $1 B$ ).

Xylem water potential $\left(\Psi_{\mathrm{x}}\right)$, foliar transpiration and temperature: The VPD (Fig. 1C) changed leaf temperature (Fig. 2C); the highest temperature was between 12:00 and 16:00 h. The $\Psi_{\mathrm{x}}$ at the beginning of the day was approximately $-1.5 \mathrm{MPa}$. Plants were able to reach up to $-4.3 \mathrm{MPa}$ at the time of the highest VPD around 13:00 $\mathrm{h}$ (Fig. 2A), always recovering initial values in the late afternoon. Plants transpiration also accompanied the peaks of higher VPD and corroborated the low $\Psi_{\mathrm{x}}$ (Fig. 2B).

Epicuticular wax (EW) characteristics and content: The EW of C. flexuosa was morphologically characterized as a crust. The total amount of wax varied from 53 to
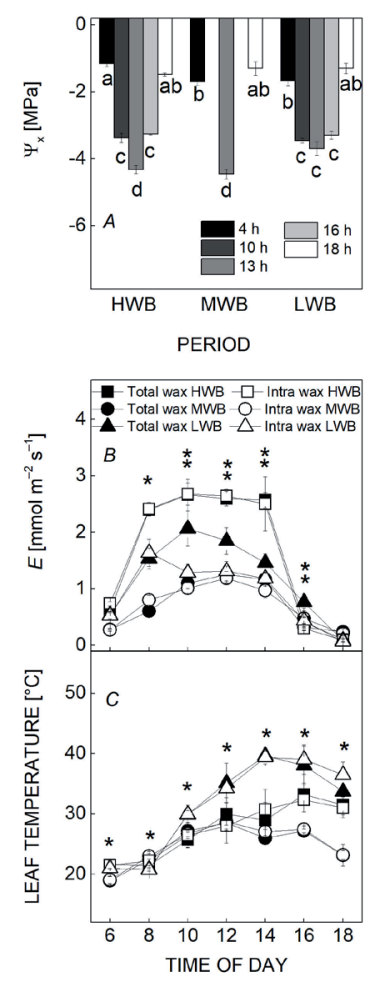

Fig. 2. Xylem water potential $\left(\psi_{\mathrm{x}}\right)(A)$; leaf transpiration rate $(E)$ $(B)$, and leaf temperature $(C)$ of Cynophalla flexuosa throughout the day and during different levels of soil water balance: HWB (high water balance), MWB (middle water balance), and LWB (low water balance) in leaves with the total wax (total wax) and in leaves that had epicuticular wax removed (intra wax). Different letters indicate differences between averages, one asterisk indicates differences between water balance levels, two asterisks indicate difference between treatments by the NewmanKeuls test $(p<0.05)(n=4 \pm \mathrm{SE})$. 
$70 \mu \mathrm{g} \mathrm{cm}^{-2}$. LWB period had the higher cuticle wax content, followed by HWB and MWB, which did not differ from each other (Table 1). On the other hand, the EW content in leaves with Arabic gum application (intra wax leaves) was between 15 to $19 \%$ lesser than that of the control. Changes in the EW concentration at leaf adaxial surface were $24 \%$ between LWB and other periods. Components found in the $C$. flexuosa EW were n-alkanes (17.2\%), including heptacosane, nonacosane, hentriacontane, and tritriacontane; fatty acid $(1.8 \%)$ octadecanoic; and the triterpenoids ( $81 \%$ ), such as: lupeol, $\alpha$-amyrin, $\beta$-amyrim, lepenon, and betulin (Table 1). Predominant compounds were triterpenoids, lupeol, and betulin, accounting for more than $50 \%$ of $C$. flexuosa wax. Among the three periods, leaves during LWB exhibited more n-alkanes and fatty acid and less triterpenes than the others.

Gas exchange and Chl $\boldsymbol{a}$ fluorescence: Gas exchange varied according to the environmental water availability during the day (Fig. $3 A, B$ ). The highest $g_{\mathrm{s}}$ and $P_{\mathrm{N}}$ values

Table 1. Epicuticular wax content $\left(\mu \mathrm{g} \mathrm{cm}^{2}\right)$ in leaves with total wax (wax) and wax removed (intra wax) from Cynophalla flexuosa collected at different levels of epicuticular wax from the adaxial surface of leaves. HWB (soil high water balance), MWB (soil middle water balance) and LWB (soil low water balance) under a seasonally dry tropical forest conditions. Different letters indicate differences between the means by the Newman-Keuls test $(p<0.05)(n=4 \pm \mathrm{SE})$.

\begin{tabular}{llll}
\hline \multicolumn{4}{l}{ Water balance } \\
Constituents [\%] & HWB & MWB & LWB \\
\hline$n$-alkanes & & & \\
Heptacosane & $2.5 \pm 0.2^{\mathrm{b}}$ & $5.4 \pm 0.2^{\mathrm{a}}$ & $2.8 \pm 0.2^{\mathrm{b}}$ \\
Nonacosane & $4.3 \pm 0.2^{\mathrm{ns}}$ & $4.3 \pm 0.1$ & $4.2 \pm 0.2^{\mathrm{a}}$ \\
Hentriacontane & $6.1 \pm 0.2^{\mathrm{b}}$ & $4.3 \pm 0.2^{\mathrm{c}}$ & $15.3 \pm 0.4^{\mathrm{a}}$ \\
Tritriacontane & $3.6 \pm 0.2^{\mathrm{b}}$ & $3.5 \pm 0.1^{\mathrm{b}}$ & $4.8 \pm 0.2^{\mathrm{a}}$ \\
$n$-fatty acids & & & \\
Octadecanoic & $1.7 \pm 0.1^{\mathrm{c}}$ & $2.0 \pm 0.1^{\mathrm{b}}$ & $9.3 \pm 0.3^{\mathrm{a}}$ \\
Triterpenes & & & \\
Lupeol & $34.0 \pm 0.5^{\mathrm{b}}$ & $28.8 \pm 0.4^{\mathrm{c}}$ & $36.7 \pm 0.6^{\mathrm{a}}$ \\
$\alpha$-amyrin & $8.7 \pm 0.2^{\mathrm{a}}$ & $6.2 \pm 0.2^{\mathrm{b}}$ & $4.4 \pm 0.2^{\mathrm{c}}$ \\
$\beta$-amyrin & $6.2 \pm 0.2^{\mathrm{a}}$ & $5.6 \pm 0.2^{\mathrm{b}}$ & $4.8 \pm 0.2^{\mathrm{c}}$ \\
Lupenon & $8.8 \pm 0.3^{\mathrm{a}}$ & $8.5 \pm 0.2^{\mathrm{a}}$ & $7.2 \pm 0.3^{\mathrm{b}}$ \\
Betulin & $20.0 \pm 0.5^{\mathrm{b}}$ & $23.3 \pm 0.2^{\mathrm{a}}$ & $7.4 \pm 0.2^{\mathrm{c}}$ \\
Wax content [ $\left.\mu \mathrm{g} \mathrm{cm}{ }^{2}\right]$ & & & \\
Total wax & $53.6 \pm 2.0^{\mathrm{c}}$ & $54.8 \pm 1.4^{\mathrm{c}}$ & $69.8 \pm 2.1^{\mathrm{a}}$ \\
Intra wax & $46.1 \pm 1.9^{\mathrm{d}}$ & $45.1 \pm 1.7^{\mathrm{d}}$ & $59.7 \pm 1.0^{\mathrm{b}}$ \\
Removed [\%] & 15 & 19 & 15 \\
\hline
\end{tabular}

occurred during the HWB period, without declining under the highest VPD around midday, regardless of the treatments. Leaf $\mathrm{WUE}_{\mathrm{i}}$ values were high during all study periods, regardless of the treatment (Fig. $3 C$ ).

The values of $\mathrm{F}_{\mathrm{v}} / \mathrm{F}_{\mathrm{m}}$ were always in the range of 0.7-0.8 (Fig. 4A), which indicates absence of damage to the photosynthetic machinery during the study period in both treatments. The EW removed caused changes in the photochemical activity around midday, between 10:00 to

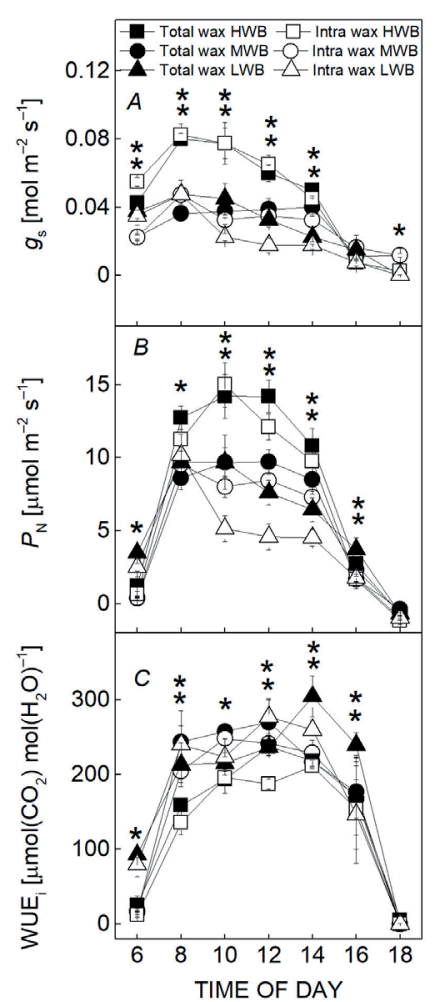

Fig. 3. Stomatal conductance $\left(g_{\mathrm{s}} ; A\right)$, net $\mathrm{CO}_{2}$ assimilation rate $\left(P_{\mathrm{N}} ; B\right)$, and intrinsic water-use efficiency $\left(\mathrm{WUE}_{\mathrm{i}} ; C\right)$ of Cynophalla flexuosa throughout the day and during different soil water balance levels: HWB (high water balance), MWB (middle water balance), and LWB (low water balance) in leaves with total wax (total wax) and in leaves that had epicuticular wax removed (intra wax). ${ }^{*}$ - differences between soil water balance levels, ${ }^{* *}$ - difference between leaf treatments by the Newman-Keuls test $(p<0.05)(n=4 \pm \mathrm{SE})$.

14:00 $\mathrm{h}$ in both treatments (Fig. $4 B, D$ ). The $\Phi_{\text {PSII values }}$ were higher in MWB when compared to the other periods (Fig. 4B). At the end of the day around 18:00 h, all reaction centers recovery showed initial values in the three analyzed periods. In $\mathrm{MWB}, \mathrm{q}_{\mathrm{P}}$ values also remained higher than that in the other periods (Fig. 4C). The NPQ was higher in HWB at 8:00, 10:00, and 16:00 h, except at 14:00 $\mathrm{h}$, where the highest rate was in LWB (Fig. 4D). As for ETR, MWB showed the lowest values in both treatments and the total wax leaves of LWB was higher when compared to others periods (Fig. 4E)

Biochemistry and antioxidative foliar metabolism: The SS leaf content in HWB showed a higher concentration of total wax leaves (Fig. 5A). When fractionated into sucrose and fructose, these sugars were not different between treatments or periods (Fig. 5B,C) as well as proteins (Fig. 5D). The FA (Fig. 5E) also did not differ, except in MWB, where it was more concentrated in intrawax leaves. The proline content differed between periods, showing an expressive increase during LWB, similar to the other treatments (Fig. $5 F$ ). The photosynthetic pigments analyzed did not change significantly between treatments or among periods (data not shown). 


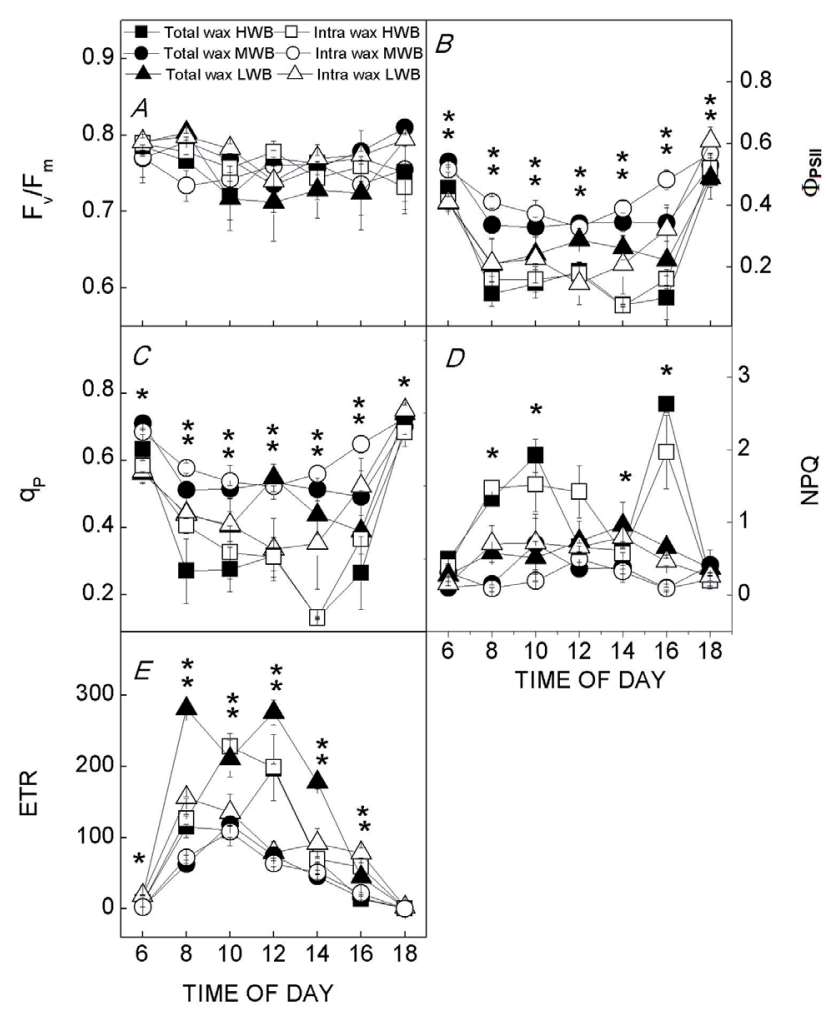

Fig. 4. Chlorophyll a fluorescence. Maximum quantum efficiency of photosystem II $\left(\mathrm{F}_{\mathrm{v}} / \mathrm{F}_{\mathrm{m}} ; A\right)$, operational efficiency of photosystem II $\left(\Phi_{\mathrm{PSII}} ; B\right)$, photochemical quenching $\left(\mathrm{q}_{\mathrm{p}} ; C\right)$, nonphotochemical quenching (NPQ; $D)$, and electron transport rate (ETR; E) of Cynophalla flexuosa throughout the day and during different soil water balance levels: HWB (high water balance), MWB (middle water balance), and LWB (low water balance) in leaves with total wax (total wax) and in leaves that had wax epicuticular removed (intra wax). * - differences between soil water balance levels, $* *$ - difference between leaf treatments by the Newman-Keuls test $(p<0.05)(n=4 \pm \mathrm{SE})$.

Changes in the antioxidative system can be seen in the SOD activity, which was higher in HWB and did not differ between treatments (Fig. 6A). CAT and APX values showed greater activity in LWB, followed by MWB and HWB, which differed from each other (Fig. $6 B, C$ ). No significant difference was found for $\mathrm{H}_{2} \mathrm{O}_{2}$, MDA between periods or between treatments (Fig. 6D,E).

Foliar anatomy: C. flexuosa is amphistomatous species (stomata on both abaxial and adaxial surfaces); therefore, stomata are in a great number at the abaxial face. On the other hand, stomata of the adaxial face are located only on the central vein and in a very low number, not counted in this study. As for stomatal density, the abaxial face is responsible for the large number of stomata per leaf, and leaves collected in the HWB period had the highest number of stomata per area (Table 2). Concerning of epidermal thickness, the adaxial face was larger and did not differ between periods. For cuticle, the result was similar except that the adaxial face showed the lowest thickness in MWB when compared to the other periods. The palisade and spongy parenchyma were thicker in leaves collected

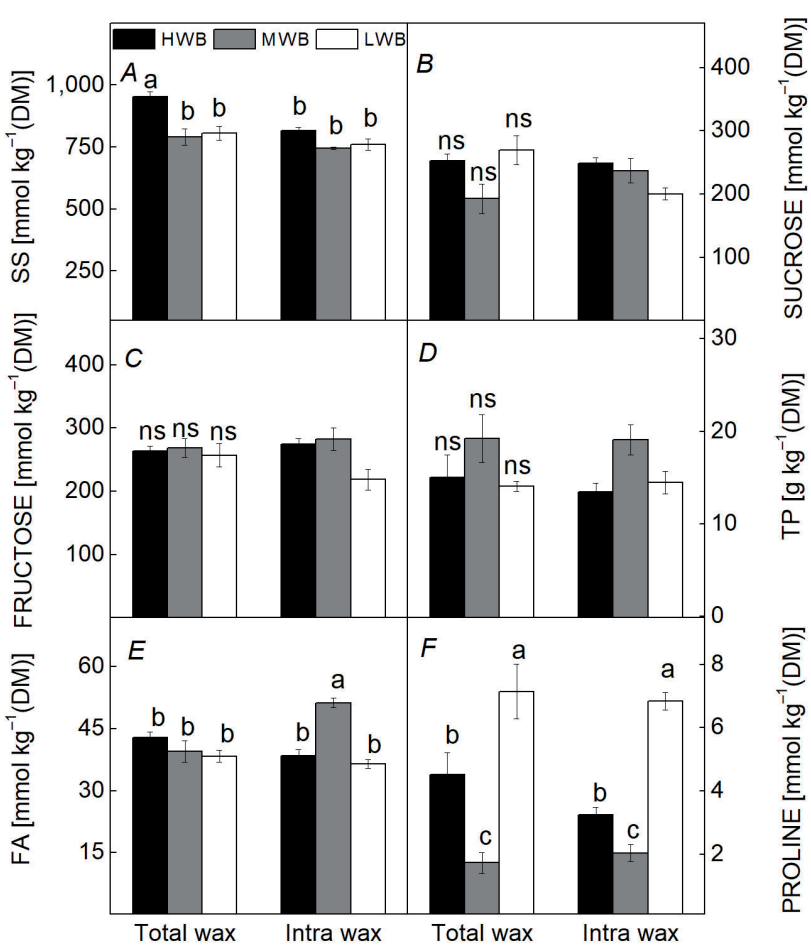

Fig. 5. Foliar metabolism. Foliar soluble sugars content (SS; $A$ ), sucrose $(B)$, fructose $(C)$, total free amino acids $(\mathrm{FA} ; D)$, proline $(E)$; total proteins (TP; $F$ ) of Cynophalla flexuosa throughout the day and during different soil water balance levels: HWB (high water balance), MWB (middle water balance), and LWB (low water balance) in leaves with total wax (total wax) and in leaves that had wax epicuticular removed (intra wax). Different letters indicate differences between the means by the Newman-Keuls test $(p<0.05)(n=4 \pm \mathrm{SE})$.

during the MWB, palisade parenchyma being thicker than spongy, when compared to the other periods. In HWB, spongy parenchyma was thicker and but not differed in the LWB. This increase in the parenchyma thickness in leaves collected during MWB reflected thickening of the mesophyll and consequently total leaf thickness, which was also larger in MWB (Table 2).

\section{Discussion}

C. Alexuosa plants changed foliar photosynthetic metabolism after EW removal, especially around midday. Our data indicate the presence of epicuticular wax on the foliar adaxial surface of this woody evergreen species as a strategy; as well as the stomata location has a specific characteristic. Dataset supports how C. flexuosa is able to maintain the physiological foliar performance, when plants are under severe irregularity of precipitation in Brazilian SDTF. High soil evaporation conditions in recent years have promoted the negative water balance for almost all the time or during the whole year. Thus, the $\Psi_{\mathrm{x}}$ decreased to around $70 \%$ at midday with the highest daily VPD. However, this evergreen can recover predawn values in the late afternoon.

C. flexuosa would be classified as anisohydric. This behavior allows the plant to maintain carbon uptake 


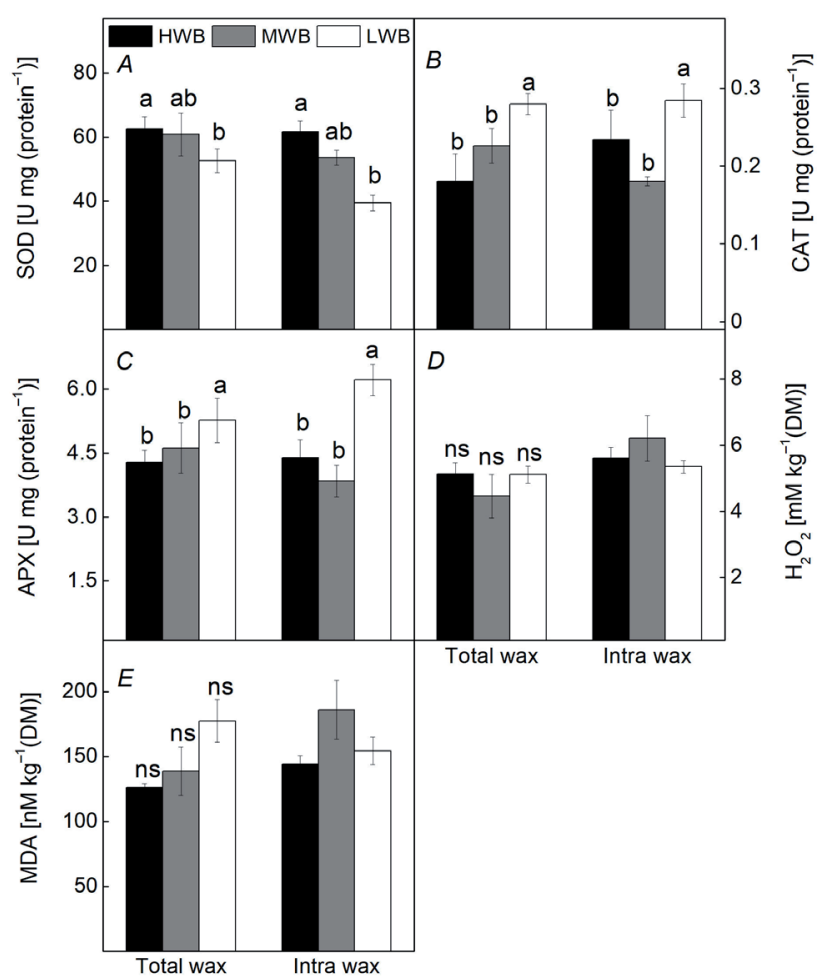

Fig. 6. Foliar antioxidative metabolism. Superoxide dismutase (SOD; $A$ ), catalase (CAT; $B)$, ascorbate peroxidase (APX; $C$ ), hydrogen peroxide $\left(\mathrm{H}_{2} \mathrm{O}_{2} ; D\right)$, and malonidialdehyde (MDA; $\left.E\right)$ of Cynophalla flexuosa throughout the day and during different soil water balance levels: HWB (high water balance), MWB (middle water balance), and LWB (low water balance) in leaves with total wax (total wax) and in leaves that had wax epicuticular removed (intra wax). Different letters indicate differences between the means by the Newman-Keuls test $(p<0.05)(n=4 \pm \mathrm{SE})$.

and growth rates even during the drought period. It is an advantage in the presence of high soil moisture because it facilitates the biomass production (Attia et al. 2015). The so fast water status recovery already late in the afternoon suggests efficient hydraulic conductivity of this evergreen (Skelton et al. 2017). Thus, the dynamic xylem water potential during the afternoon could be indicative of rapid water conduction and/or deep rooting.

C. flexuosa EW has crustal structure, which is a tolerance trait for arid environments. Crust wax with horizontal plates is more efficient at reflectance of intense radiation compared to vertical forms, such as crystals (Grant 2003). Previous studies have shown that species under intense radiation may lose EW crystal structure (Mohammadian et al. 2007, Ni et al. 2014). Therefore, wax crystals, when present on the leaf surface, could fuse with high UV-B radiation in both adaxial and abaxial surfaces, but the effect is more prominent on the upper surface due to the direct exposure to radiation ( $\mathrm{Ni}$ et al. 2014).

Thus, environmental conditions, such as high light intensity, low air humidity, and high temperature seen in the LWB, are factors that justify some types of epicuticular waxes in SDTF regions (Oliveira and Salatino 2000). In fact, high foliar EW content could have been result of low soil water balance in this period, which had greater deficit around $-150 \mathrm{~mm}$ (Samdur et al. 2003, Mohammadian et al. 2007, Santos et al. 2014). The 15\% EW removed from leaves was sufficient to decrease the gas exchange and Chl $a$ fluorescence. Under LWB these leaves achieved the lowest $\Psi_{\mathrm{x}}$ after midday. However, there was no damage to the photosynthetic machinery, always maintaining $\mathrm{F}_{\mathrm{v}} / \mathrm{F}_{\mathrm{m}}$ values between 0.75 and 0.80 .

One of the leaf traits, which would help in maintaining the photosynthetic machinery, would be the cuticle and its composition. Thick cuticle is not a support against water loss (Oliveira et al. 2003). Thus, the chemical wax composition becomes more important than the quantity under severe conditions (Figueiredo et al. 2012). The n-alkanes found in the C. flexuosa EW are effective as promoters of water impermeability on Caatinga species (Oliveira and Salatino 2000, Figueiredo et al. 2012). The presence of n-alkanes in EW is also an additional trait to support drought tolerance of this species. Indeed, the fatty acid content found also has the role to protect against the transpiration of leaves, but less efficient when compared to alkanes (Oliveira et al. 2003). The triterpenoids have more compacted molecular geometry and can be found in higher concentrations in intracuticular wax (Racovita and Jetter 2016). This group has been reported as a protection against herbivores in leaves (Oliveira et al. 2012), being common in deciduous SDTF trees (Medeiros et al. 2017). In the present study, the presence of the high amount of triterpenoids during HWB and MWB suggests the prevention against herbivores, which is fundamental to protect the leaf area of evergreen species. On the other hand, under LWB, there was a greater investment in n-alkanes and fatty acids, while a decrease of the triterpenes was observed; it indicates that the leaf was prepared to lose the minimum water as possible in periods of severe water deficits.

In LWB, the edaphoclimatic conditions decreased $g_{\mathrm{s}}$ values of intra-wax leaves from 30 to $50 \%$ at midday with the highest VPD, as seen in woody species by Figueiredo et al. (2012) and Medeiros et al. (2017) both in the Caatinga environment. However, in C. flexuosa, $g_{\mathrm{s}}$ and $P_{\mathrm{N}}$ daily behavior is typical anisohydric, gas-exchange rates are always maintained to detriment of $\psi_{\mathrm{x}}$ throughout the day (Guha and Reddy 2014, Roman et al. 2015). In fact, this species showed a low investment in water loss reduction in EW components during this season. Furthermore, anisohydric behavior may be dangerous for species in years of prolonged drought, due to low water potentials (Tardieu and Simonneau 1998, Roman et al. 2015). Therefore, wax removal changed leaf behavior throughout the day in the driest period (LWB), although C. flexuosa has shown high resilience in drought tolerance. Thus, it was able to maintain $\mathrm{CO}_{2}$ assimilation at the same time with high $\mathrm{WUE}_{\mathrm{i}}$, even under values of $6 \mathrm{kPa}$ VPD.

The $F_{v} / F_{m}$ values were always recovered at the end of the sunlight period, even under high radiation, the values were kept around 0.8, indicative of no damage; at same time, $\Phi_{\mathrm{PSII}}$ and $\mathrm{q}_{\mathrm{P}}$ decreased during intense PPFD around midday. On the other hand, only when in HWB and high luminous intensity NPQ values increased, however, excess of energy dissipation mechanism efficiency was 


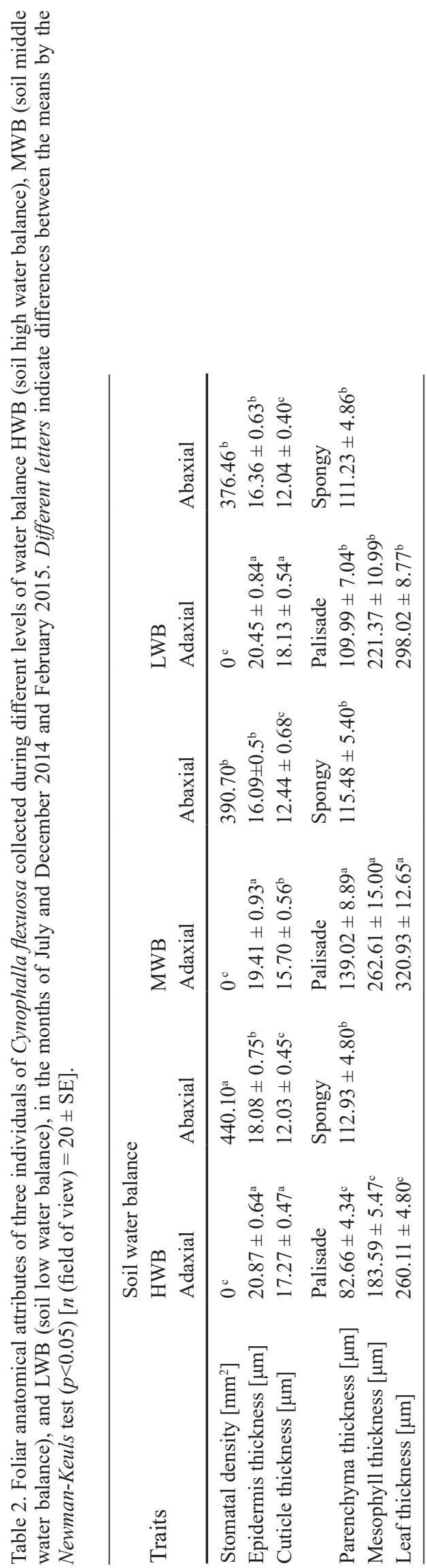

demonstrated, maintaining $\mathrm{F}_{\mathrm{v}} / \mathrm{F}_{\mathrm{m}}$ values above 0.75 (Sales et al. 2013). Under MWB, the highest ETR values in total wax leaves did not lead to the highest $P_{\mathrm{N}}$ at same period, although values were higher compared to intra-wax leaves. This excess of electrons may have been sunk in biochemical adjustments, such as higher photorespiration rate and/or proline production.

The increased FA content in intra-wax leaves could be related to the leaf antioxidant system (Oliveira et al. 2014), such as happens with proline during LWB. Proline can exert antioxidant function under conditions of water restriction in some species (Liu et al. 2011). The behavior of this amino acid leads to several questions regarding the role played in foliar metabolism, including native and invasive woody species found under SDTF conditions (Oliveira et al. 2014).

Increased antioxidative enzyme activity is expected in evergreen woody species from semiarid regions during the dry season (Hu et al. 2013). Thus, CAT and APX enhanced activity during LWB may be due to low xylem water potential in the period in order to prevent and protect leaf tissue against possible oxidative stress (Liu et al. 2011, Mafakheri et al. 2011). EW removal did not alter the activity of these enzymes. Thus, low water availability may be responsible for such changes. Oxidative stress and consequent membrane damage seem to be controlled, as suggested by the MDA and $\mathrm{H}_{2} \mathrm{O}_{2}$ values. Simultaneously, SOD activity was gradually decreasing with soil water availability. On the other hand, proline values were the highest throughout the study period. The correlation between leaf proline content and SOD activity was significant during MWB, maybe an indication of the antioxidative role of this amino acid (Liu et al. 2011).

C. Alexuosa leaves not only changed biochemical metabolism throughout the seasons, but also performed morphoanatomic adjustments. The low stomata frequency on the adaxial side and exclusively present on the main vein suggests $C$. flexuosa is functionally hypoestomatic (Torrecilla et al. 2008). This low stomata number on this face would be leaf protection against excessive water loss and intense radiation during the driest months of the year (Ni et al. 2015). In fact, the absence of pores along adaxial cuticle would allow the homogenous wax layer formation; therefore, a barrier with greater resistance to water flow. In addition, the maintenance of constant $g_{\mathrm{s}}$ values throughout the day may have been influenced by the proximity to the water-conducting vessels, since foliar hydraulic conductivity is one of the main regulators of stomatal behavior (Sack and Scoffoni 2013).

The most severe conditions were also reflected in the leaf structure. Under MWB, it was thicker and palisade parenchyma larger than spongy. These changes would be common in SDTF conditions, which would increase mesophilic conductance, favoring $\mathrm{CO}_{2}$ assimilation rate (Adachi et al. 2013). In fact, leaves of woody species showed larger total leaf thickness, the palisade parenchyma being larger and correlated with greater photosynthetic activity (Vemmos et al. 2013). In the present study, under HWB, C. flexuosa produced thinner leaves with greater intracellular space, due to thicker spongy parenchyma. 
Concomitantly, these leaves have higher stomatal density, which could suggest thinner leaves and high-intensity of gas exchange (Hetherington and Woodward 2003) and rapid $\mathrm{CO}_{2}$ assimilation. These leaves would be those that would remain in the rainy season.

In conclusion, our results corroborate the initial hypothesis of epicuticular wax content and composition having great importance and being determinant to physiological traits in this evergreen species. The absence of epicuticular wax in adaxial epidermis slightly changed the primary foliar metabolism throughout the year, as well as morpho-anatomic traits of leaves. Thus, despite the soil water balance variation, C. flexuosa foliar metabolism showed significant resilience. Under the study conditions, this species was anisohydric, the xylem water potential was reduced in the moments of the highest VPD and recovery in the late afternoon, regardless of the period of the year. On the other hand, $\mathrm{CO}_{2}$ assimilation remained stable and high for a tree species, except in the driest period and in leaves without epicuticular wax. Future studies on hydraulic relationships and detailed $C$. flexuosa hydraulic conduction can help complete understanding of its performance.

\section{References}

Adachi S., Nakae T., Uchida M. et al:: The mesophyll anatomy enhancing $\mathrm{CO}_{2}$ diffusion is a key trait for improving rice photosynthesis. - J. Exp. Bot. 64: 1061-1072, 2013.

Alexieva V., Sergiev I., Mapelli S. et al.: The effect of drought and ultraviolet radiation on growth and stress markers in pea and wheat. - Plant Cell Environ 24: 1337-1344, 2001.

Attia Z., Domec J.C., Oren R. et al.: Growth and physiological responses of isohydric and anisohydric poplars to drought. $-\mathrm{J}$. Exp. Bot. 66: 4373-4381, 2015.

Bates L.S., Waldren R.P., Teare I.D.: Rapid determination of free proline for water-stress studies. - Plant Soil 39: 205-207, 1973.

Bradford M.: Rapid and quantitative method for quantitation of microgram quantities of protein utilizing the principle of protein-dye binding. - Anal Biochem. 72: 284-252, 1976.

Cakmak I., Horst W.J.: Effect of aluminium on lipid peroxidatios, superoxide dismutase,catalase, and peroxidase activities in root tips of soybean (Glycine max). - Physiol. Plantarum 83: 463-468, 1991 .

Chaves M.M., Costa J.M., Zarrouk O. et al.: Controlling stomatal aperture in semi-arid regions - The dilemma of saving water or being cool? - Plant Sci. 251: 54-64, 2016.

Diego N.D., Pérez-Alfocea F., Cantero E. et al.: Physiological response to drought in radiata pine: phytohormone implication at leaf level. - Tree Physiol. 32: 435-449, 2012.

DuBois M., Gilles K.A., Hamilton J.K. et al.: Colorimetric method for determination of sugars and related substances. Anal. Chem. 28: 350-356, 1956.

Figueiredo K.A., Oliveira M.T., Oliveira A.F.M. et al.: Epicuticular-wax removal influences gas exchange and water relations in the leaves of an exotic and native species from a Brazilian semiarid region under induced drought stress. Aust. J. Bot. 60: 685-692, 2012.

Figueiredo K.V., Oliveira M.T., Arruda E.C.P. et al.: Changes in leaf epicuticular wax, gas exchange and biochemistry metabolism between Jatropha mollissima and Jatropha curcas under semiarid conditions. - Acta Physiol. Plant. 37: $108,2015$.

Foreman D., Gaylor L., Evans E. et al.: A modification of the roe procedure for determination of fructose in tissues with increased specificity. - Anal Biochem. 56: 584-590, 1973.

Franklin G.: Preparation of thin sections of synthetic resins and wood-resin composities and a new macerating method of wood. - Nature 155: 51, 1945.

Giannopolitis C.N., Reis S.K.: Superoxide dismutase I. Occurrence in higher plants. - Plant Physiol. 59: 309-314, 1977.

Grant R.H., Heisler G.M., Gao W. et al.: Ultraviolet leaf reflectance of common urban trees and the prediction of reflectance from leaf surface characteristics. - Agr. Forest Meteorol. 120: 127-139, 2003.

Guha A., Reddy A.R.: Leaf gas exchange, water relations and photosystem-II functionality depict anisohydric behavior of drought-stressed mulberry (Morus indica, cv. V1) in the hot semi-arid steppe agroclimate of Southern India. - Flora 209: 142-152, 2014.

Guhling O., Kinzler C., Dreyer M. et al.: Surface composition of myrmecophilic plants: cuticular wax and glandular trichomes on leaves of Macaranga tanarius. - J. Chem. Ecol. 31: 23232341, 2005 .

Handel E.V.: Direct microdetermination of sucrose. - Anal. Biochem. 22: 280-283, 1968.

Havir E.A., McHale N.A.C.: Biochemical and developmental characterization of multiple forms of catalase in tobacco leaves. - Plant Physiol. 84: 450-455, 1987.

Hetherington A.M., Woodward F.I.: The role of stomata in sensing and driving environmental change. - Nature 424: 901908, 2003.

Hu W., Huang C., Deng X. et al.: TaASR1, a transcription factor gene in wheat, confers drought stress tolerance in transgenic tobacco. - Plant Cell Environ. 36: 1449-1464, 2013.

IPCC: Climate Change 2013. The Physical Science Basis. Working Group I Contribution to the Fifth Assessment Report of the Intergovernmental Panel on Climate Change. Pp. 1535. Cambridge University Press, Cambridge and New York, 2013.

Jetter R., Schäffer S.: Chemical composition of the Prunus laurocerasus leaf surface. Dynamic changes of the epicuticular wax film during leaf development. - Plant Physiol. 126: 17251737, 2001.

Kerstiens G.: Signalling across the divide: a wider perspective of cuticular structure - function relationships. - Trends Plant Sci. 1: 125-129, 1996.

Kramer P.J., Boyer J.S.: Water Relations of Plants and Soils. Pp. 495. Academic Press, San Diego 1995.

Lichtenthaler H.: Chlorophylls and carotenoids: pigments of photosynthetic biomembranes. - Methods Enzymol. 148: 350$382,1987$.

Lima A.L.A., Sampaio E.V.S.A.B., Castro C.C. et al.: Do the phenology and functional stem attributes of woody species allow for the identification of functional groups in the semiarid region of Brazil? - Trees 26: 1605-1616, 2012.

Liu C., Liu Y., Guo K. et al.: Effect of drought on pigments, osmotic adjustment and antioxidant enzymes in six woody plant species in karst habitats of southwestern China. Environ. Exp. Bot. 71: 174-183, 2011.

Mafakheri A., Siosemardeh A., Bahramnejad B. et al.: Effect of drought stress and subsequent recovery on protein, carbohydrate contents, catalase and peroxidase activities in three chickpea (Cicer arietinum) cultivars. - Aust. J. Crop Sci. 5: 1255-1260, 2011.

Maxwell K., Johnson G.: Chlorophyll fluorescence - a pratical guide. - J. Exp. Bot. 51: 659-668, 2000.

Medeiros C.D., Falcão, H.M., Almeida-Cortez J. et al.: Leaf epicuticular wax content changes under different rainfall regimes, and its removal affects the leaf chlorophyll content and gas 
exchanges of Aspidosperma pyrifolium in a seasonally dry tropical forest. - S. Afr. J. Bot. 111: 267-274, 2017.

Mohammadian M.A., Watling J.R., Hill R.S.: The impact of epicuticular wax on gas-exchange and photoinhibition in Leucadendron lanigerum (Proteaceae). - Acta Oecol. 31: 93101, 2007.

Moore S., Stein W.: A modified ninhydrin reagent for the photometric determination of amino acids and related compounds. - J. Biol. Chem. 221: 907-913, 1954.

Morales M., Garcia Q.S., Munné-Bosch S.: Ecophysiological response to seasonal variations in water availability in the arborescent, endemic plant Vellozia gigantea. - Tree Physiol. 35: 253-265, 2015.

Nakano Y., Asada K.: Hydrogen peroxide is scavenged by ascorbate-specific peroxidases in spinach chloroplast. - Plant Cell Physiol. 22: 867-880, 1981.

Ni Y., Xia R., Li J.: Changes of epicuticular wax induced by enhanced UV-B radiation impact on gas exchange in Brassica napus. - Acta Physiol. Plant. 36: 2481-2490, 2014.

Ni Y., Sun Z., Huang X. et al.: Variations of cuticular wax in mulberry trees and their effects on gas exchange and postharvest water loss. - Acta Physiol. Plant. 37: 112, 2015.

Oliveira A.F.M., Salatino A.: Major constituents of the foliar epicuticular waxes of species from the Caatinga and Cerrado. -Z. Natuforsch. C 55: 688-692, 2000.

Oliveira A.F.M., Meirelles S.T., Salatino, A.: Epicuticular waxes from Caatinga and Cerrado species and their efficiency against water loss. Anais Acad. Bras. Ciênc. 75: 431-439, 2003.

Oliveira K.N., Espírito-Santo M.M., Silva J.O. et al.: Ontogenetic and temporal variations in herbivory and defense of Handroanthus spongiosus (Bignoniaceae) in a Brazilian tropical dry forest. - Environ. Entomol. 41: 541-550, 2012.

Oliveira M.T., Medeiros C.D., Frosi G. et al.: Different mechanisms drive the performance of native and invasive woody species in response to leaf phosphorus supply during periods of drought stress and recovery. - Plant Physiol. Bioch. 82: 66-75, 2014.

Oliveira M.T., Souza G.M., Pereira S. et al.: Seasonal variability in physiological and anatomical traits contributes to invasion success of Prosopis juliflora in tropical dry forest. - Tree Physiol. 37: 326-337, 2017.

Poorter L., Markesteijn L.: Seedling traits determine drought tolerance of tropical tree species. - Biotropica 40: 321-341, 2008.

Purvis M.J., Collier D.C., Walls D.: Laboratory Techniques in Botany. Pp. 371. Butterworths, London 1964.

Racovita R.C., Jetter R.: Composition of the epicuticular waxes coating the adaxial side of Phyllostachys aurea leaves: Identification of very-long-chain primary amides. Phytochemistry 130: 252-261, 2016.

Riederer M., Schreiber L.: Protecting against water loss: analysis of the barrier properties of plant cuticles. - J. Exp. Bot. 52:
2023-2032, 2001.

Riederer M.: Introduction: biology of the plant cuticle. - In: Riederer M.; Müller C. (ed.): Biology of the Plant Cuticle. Publishing Ltd., Würzburg, Germany 2006.

Robbins N.S., Pharr D.M.: Effect of restricted root growth on carbohydrate metabolism and whole plant growth of Cucumis sativus L. - Plant Physiol. 87: 409-413, 1988.

Rolim G.S., Sentelhas P.C., Barbieri V.: [Spreadshets in Excel ${ }^{\mathrm{TM}}$ environment to calculation of water balance: normal, sequencial, culture, and potential, real produtivity.] - Rev. Bras. Agrometeorol. 6: 133-137, 1998. [In Portuguese]

Roman D.T., Novick K.A., Brzostek E.R. et al.: The role of isohydric and anisohydric species in determining ecosystem-scale response to severe drought. - Oecologia 179: 641-654, 2015.

Sack L., Scoffoni C.: Leaf venation: structure, function, development, evolution, ecology and applications in the past, present and future. - New Physiol. 198: 983-1000, 2013.

Sales C.R.G., Ribeiro R.V., Silveira J.A.G. et al.: Superoxide dismutase and ascorbate peroxidase improve the recovery of photosynthesis in sugarcane plants subjected to water deficit and low substrate temperature. - Plant Physiol. Bioch. 73: 326-336, 2013.

Samdur M.Y., Manivel P., Jain V.K. et al.: Genotypic differences and waterdeficit induced enhancement in epicuticular wax load in peanut. - Crop Science 43: 1294-1299, 2003.

Santos M.G., Oliveira M.T., Figueiredo K.V. et al.: Caatinga, the Brazilian dry tropical forest: can it tolerate climate changes? Theor. Exp. Plant Physiol. 26: 83-99, 2014.

Skelton R.P., Brodribb T.J., McAdam S.A.M. et al.: Gas exchange recovery following natural drought is rapid unless limited by loss of leaf hydraulic conductance: evidence from an evergreen woodland. - New Phytol. 215: 1399-1412, 2017.

Tardieu F., Simonneau T.: Variability among species of stomatal control under fluctuating soil water status and evaporative demand: modelling isohydric and anisohydric behaviours. - J. Exp. Bot. 49: 419-432, 1998.

Tomlinson K.W., Poorter L., Sterck F.J. et al.: Leaf adaptations of evergreen and deciduous trees of semi-arid and humid savannas on three continents. - J. Ecol. 101: 430-440, 2013.

Torrecilla P., Castro M., Lapp M.: [Foliar morphoanatomy in specimens of Capparis flexuosa (L.) L. (Capparaceae) growing in three different localities of Aragua state (Venezuela).] Ernstia 19: 35-54, 2008. [In Castilian]

Trethewey R.N., Geigenberger P., Riedel K. et al:: Combined expression of glucokinase and invertase in Potato tubers leads to a dramatic reduction in starch accumulation and a stimulation of glycolysis. - Plant J. 15: 109-118, 1998.

Vemmos S.N., Petri E., Stournaras V.: Seasonal changes in photosynthetic activity and carbohydrate content in leaves and fruit of three fig cultivars (Ficus carica L.). - Sci. Hortic.Amsterdam 160: 198-207, 2013.

(C) The authors. This is an open access article distributed under the terms of the Creative Commons BY-NC-ND Licence. 